\title{
El error y la negligencia en la actividad de riesgo materialmente jurisdiccional: una realidad jurídica y social pendiente a resolver
}

\author{
Carlos Alberto Mejías Rodríguez ${ }^{1}$ \\ Michel Elías Fillad Flores ${ }^{2}$
}

\begin{abstract}
In all the social contexts, an to impart of appropriate justice and proba, it has always been yearned by the actionable ones, justification that allows at the same time to understand it as an instrument of rational gobernabilidad, and I don't eat act of power; for that reason she should be validated and legitimated in any supposition to achieve the social acceptance, since the artificial security and therefore the freedom, depends on the type of judges that he/she enjoys or suffer a society. The jurisdictional activity authorizes to make what the law confers them, and the irregular exercise of that medical right when it is abusive or abnormally permissive, it admits harmful facts, for it the functionality in the an to impart of justice, it should be in agreement to the imperatives taxes of the licit of its ruled medical activity and foregone, so that it can be properly sanctioned if irregularity exists in the performance. That aspiration constitutes the essential objective of this work that enunciates the existent problem regarding the error and the negligence in the environment of the imparticion of justice and the birdcall of achieving that the norm welcomes the jurisdictional functions as irregular administrative activities of risk for the society.
\end{abstract}

Key Words: Negligence, risk activity.

Resumen. En todos los contextos sociales, una impartición de justicia adecuada y proba, siempre ha sido anhelada por los justiciables, justificación que permite a la par entenderla como un instrumento de gobernabilidad racional, y no como acto de poder; por eso ella debe ser validada y legitimada en cualquier supuesto para lograr la aceptación social, ya que la seguridad jurídica y por tanto la libertad, depende del tipo de jueces que disfrute o padezca una sociedad. La actividad jurisdiccional faculta hacer lo que la ley les confiere, y el ejercicio irregular de ese derecho facultativo cuando es abusivo o irregularmente permisivo, admite hechos dañosos, por ello la funcionalidad en la impartición de justicia, debe ser acorde a los imperativos impuestos de la licitud de su actividad facultativa reglada y previsible, para que pueda ser debidamente sancionada si existe irregularidad en la actuación. Esa aspiración constituye el objetivo esencial de este trabajo que enuncia la problemática existente respecto al error y la negligencia en el ámbito de la impartición de justicia y el reclamo de lograr que la norma acoja las funciones jurisdiccionales como actividades administrativas irregulares de riesgo para la sociedad.

Palavras-chave: negligencia, actividad de riesgo.

\footnotetext{
${ }^{1}$ Doctor en Ciencias Jurídicas por la Universidad de la Habana, Cuba. Profesor titular en Derecho penal. Email: mejiascarlosalberto@gmail.com

${ }^{2}$ Doctor en Derecho por el Centro de Ciencias Jurídicas de Puebla. Abogado litigante en el Estado de Puebla, México. Email: mifloflo@ hotmail.com
} 


\section{Introdução}

La administración pública del Estado en cumplimiento al principio de legalidad, bajo la ley facultativa, según sea la función que desempeña, es instrumentada para la protección de los gobernados, por ello, contrarrestar cualquier arbitrariedad del poder público que lesione bienes o derechos de particulares debe ser vigorizada por la ley, otorgando al particular en esa instrumentación el derecho a la indemnización restaurativa, por la más elemental noción de equidad y justicia.

Son reconocidas por la doctrina y la ley, las actividades irregulares de los órganos jurisdiccionales en el ejercicio de sus funciones, otorgándosele las características de responsabilidad directa, ya sean objetivas - con implicación de negligencia, dolo o intencionalidad - en la realización del daño; o aquéllas de índole subjetiva las cuales se apoyan en la teoría del riesgo, por ausencia de intencionalidad. Contexto que a la par establece límites y puntos de contactos entre éstas y las facultades que le amparan al órgano jurisdiccional en base a los principios de independencia y autonomía judicial; cuyas atribuciones además implican, que tanto la interpretación como la toma de decisiones de las autoridades sean concordantes al contenido legal y al cumplimiento irrestricto de las garantías y principios que exigen la impartición de justicia por los funcionarios judiciales.

En la actualidad ante la presencia constante de irregularidades por parte de los funcionarios juridiciales ${ }^{3}$ y como parte del Estado de Derecho, resulta de especial interés que se decida el encausamiento del operador judicial y la justicia restaurativa, ya sea por supuestos relacionados con las actividades irregulares de los órganos jurisdiccionales en el ejercicio de sus funciones, basados en el nexo de atribución por la actividad desplegada, por lo que orgánicamente, la denominación de las irregularidades y su instrumentación, de una parte darán más certeza al juez en su encomienda constitucional, clarificándose así la función jurisdiccional y de otra, le otorgarán las pautas necesarias en caso de responsabilidad del Estado para compensar a los particulares quienes no tienen la obligación de soportar los daños causados por la actividad irregular en el ejercicio de las funciones

\footnotetext{
${ }^{3}$ Las sentencias condenatorias a México ponen en evidencia fallas importantes sobre protección, defensa y ejercicio efectivo de los derechos humanos en México; han servido para hacer evidente esta situación y para hacer conciencia de que hay que cambiar de rumbo, uno plenamente dirigido a su máxima garantía. Estas resoluciones también han generado un gran debate sobre su obligatoriedad, cumplimiento, efectos y participación de los diferentes operadores jurídicos, entre otras cosas. RANGEL Hernández Laura. Sentencias condenatorias al Estado mexicano dictadas por la Corte Interamericana de Derechos Humanos y sus implicaciones en el orden jurídico nacional. Revista. IUS vol.5 no. 28 Puebla jul./dic. 2011
} 
judiciales.

Los temáticas que integran este ensayo, pretenden evaluar este fenómeno social de total trascendencia para el quehacer jurídico latinoamericano, muy especialmente para los operadores judiciales, quienes en su contenido podrán determinar la necesidad de trazar determinadas pautas en la exigibilidad de las responsabilidades que se contraen en el desempeño de sus funciones.

\section{Excurso sobre el principio de precaución en la actividad materialmente jurisdiccional}

La reciprocidad entre las sociedades - globalización y mundialización - interdependientes, pero afines, reconocen que existimos como sociedad de riesgos heredados y nuevos, por ello en cualquier actividad se debe instruir funcionalmente el principio de precaución como evitación del daño, adaptándose a través de regulaciones precisas y protocolos exactos, toda vez que cuando es calculado el riesgo, utilizando el principio de precaución, el peligro disminuye, y el daño es evitado, siempre que la decisión del hombre de asumir la hipótesis descrita en el deber de cuidado advierta que es riesgo permitido objetivamente.

En función del interés público, el legislador tiene que abandonar la idea de que el mejoramiento de la impartición de justicia radica solamente en el derecho sustantivo o adjetivo, pues ello de ninguna manera lleva consigo un mejor logro de los objetivos de la justicia material sino más bien acarrea mayor afectación de otros intereses y pérdida de credibilidad hacia las instituciones.

La actividad jurisdiccional será adecuada a la legalidad, si en su discurso jurídico entraña una instrumentación orgánica ajustada a los principios de independencia y autonomía tal y como lo establecen las constituciones federales y locales; instrumentación orgánica funcional que corrobora la validez jurídica de su encomienda cuando sea ajustada a la necesidad social en un modelo que esté acorde a la confianza que los justiciables han depositado en el Estado.

La legitimidad de la actividad jurisdiccional remite además a explicar el origen de la actividad materialmente jurisdiccional y a la necesidad de saber los límites de la impartición de justicia que han llevado a la sociedad a acatar y cumplir sus determinaciones. De esa forma la legitimidad se torna como indispensable con relación al bien común, y es en el ámbito de la impartición de justicia, la infracción a una norma relativa a la función jurisdiccional, en forma de sanción la que asegura el deber impuesto como límite del poder facultado. 
Al respecto un antecedente de aplicación del principio de precaución, lo es en donde existen riesgos que son todavía inciertos, como elementos de gestión de riesgo, función de análisis de riesgos y de gestión del riesgos ${ }^{4}$ y que por su estructuración tiene mayor aceptación en el manejo de riesgos actuales, también lo es que se ha dispersado a otras áreas de las ciencias humanísticas, mismas que empiezan a utilizarlo con mayor frecuencia.

No puede garantizarse la seguridad de bienes jurídicos ante cualquier forma de riesgo o peligro a los mismos, pero ante la inseguridad de la impartición de justicia, y al incorporase instrumentalmente a la función jurisdiccional se le da respuesta a la necesidad de reconducir el riesgo y prevenirlo o limitarlo en lo posible.

La precaución como principio del quehacer jurisdiccional, admite intrusiones para evitar los riesgos, alertando al impartidor de justicia el atender su deber de cuidado, como condición relativa a la responsabilidad que se le pudiera reclamar al Estado por los daños que con motivo de su actividad administrativa irregular, cause a los bienes o derechos de los particulares. Es así que bajo esa premisa, los particulares tienen derecho a una indemnización conforme a las bases, límites y procedimientos que establezcan las leyes, por los daños que con motivo de la actividad administrativa irregular se cause en sus bienes o derechos, recordando que la impartición de justicia es una actividad administrativa.

Se ha indicado que la precaución surge en forma de principio bastante útil para vislumbrar y evitar daños futuros, siendo la forma de enfrentar las nuevas e imprevistas situaciones de riesgo creadas por la transformación en la impartición de justicia, con auxilio de las tradicionales herramientas éticas y jurídicas. Tradicionalmente en el derecho, la prevención ha sido la idea de la previsión o de la previsibilidad, buscando la reducción de los riesgos y la probabilidad de los mismos.

Sin embargo el principio de precaución es distinto del principio de prevención, por lo que se establece como - la capacidad que debe tener el ser humano para discernir y decidir con anticipación el curso de acción más adecuado de las cosas, evitando el daño- y para evitar confusiones, es necesario precisar que la precaución se refiere a efectos que, aunque sean evidentes, no son identificables.

\footnotetext{
${ }^{4}$ COMISIÓN DE LAS COMUNIDADES EUROPEAS. Comunicación de la Comisión sobre el recurso al principio de precaución. Bruselas, 2 de febrero de 2000 Disponible en: http://www.lugo.es/ws/telefonia/docs/04comunicacion_de_la_ue_sobre_principio_de_precaucion_feb.pdf Acceso el 16 enero de 2016.
} 
Por su parte, la prevención se refiere a un daño conocido cuya posibilidad se echa de ver anticipadamente, el principio de precaución funciona de manera racional, es decir, delante de un peligro concreto, por tanto, su incorporación constituye un importante instrumento jurídico ya puesto en práctica en asuntos vinculados a la protección del medio ambiente y ahora puesto a disposición de los poderes del Estado, como principio general de derecho para una protección más eficiente del presente y del futuro de la humanidad en distintas áreas del saber.

La precaución también justifica acciones en un ambiente de incertidumbre en que los riesgos son evidentes, aunque no probados, La sociedad puede interpretar que la responsabilidad está diluida cuando no se puede elegir un causante culpable del riesgo, sea una persona o una organización, supuesto que convalida la necesidad de instrumentación en actividades conjuntas o colegiadas, mediante funciones distribuidas adecuadamente, mismas que son necesarias para la imputación individualizada objetivamente cuando se realiza una infracción y por causación se produce la lesión al bien jurídicamente encomendado, como pudiera ocurrir en la actividad materialmente jurisdiccional.

Por el principio de causación se atribuye la responsabilidad a quien produce el riesgo, pero esa responsabilidad no puede ser imputada a quien termina lo inevitable, por lo cual el principio de precaución puntualmente disipa la ignorancia en un terreno de incertidumbre y riesgos, ya que la ignorancia culpable es uno de los elementos que se busca disuadir.

La precaución es diligencia, identifica, vigila y evalúa la incertidumbre de la asunción del riesgo en la protección social; la ausencia de medidas reguladoras no es razón para la no adopción de medidas, ya que la gobernabilidad debe ser ejecutada a través de leyes específicas que contengan protocolos de acción específicos en el deber de precaución, para lograr consenso y entendimiento social, directrices que no son actuales y fueron refrendadas entre otros por Aristóteles quien en su momento sentenció: “..la prudencia en hacer buenas y saludables leyes para el buen gobierno de todos, a quien en su lengua llama nomothesia; la prudencia de juzgar bien las causas y contiendas que se ofrecen entre los ciudadanos, la cual parte se llama dicastice, que quiere decir judiciaria; la tercera, prudencia en el proveer las cosas tocantes al vivir y menester de la vida, la cual propiamente quedó con el nombre de disciplina de república. Estas tres partes bien regida son las que conservan el estado de las ciudades, reinos y provincias, y las que las destruyen, no 
administradas como deben."5

Los nuevos procesos en la administración pública, impulsan a tomar medidas basadas en el principio de precaución; aunque es cierto que la administración pública, no necesita obligatoriamente de la participación de la sociedad para adoptar muchas decisiones de su competencia, pero es un tema de interés común de todas las partes involucradas y de la sociedad como un todo, por lo cual la participación de la sociedad en el análisis y evaluación de riesgos en cualquier ámbito de la administración pública permite que se administre con más responsabilidad su destino, y al mismo tiempo inhibe manejos a través de falsas o deficientes informaciones.

\section{Error y negligencia materialmente jurisdiccional}

Para el tema en estudio, la cualificación del ejercicio profesional en la función de impartición de justicia, al margen de su origen administrativo, tiene su inicio en ser una actividad profesional especializada, en mayor demanda de los servicios que ofrece, y del bienestar reclamado en donde socialmente se desarrolle, por ello como conceptualiza Roldán: “ ...la profesión puede definirse como una capacidad calificada con la que una persona a través de su actividad realiza su vocación dentro de un trabajo elegido, que determina su participación en la sociedad, le sirve de medio de subsistencia y que a la vez la valora positivamente en la economía del país."6

En cualquier ámbito el aumento de necesidades profesionales se engloba en dos vertientes, una en el entendido de mayores conocimientos y/o destrezas y otro en la adecuada diligencia ofertada, dando con ello seguridad entre el profesional y sociedad. Los conocimientos y/o destrezas como cualificación, son supuestos que al tener el profesionista desplaza por lógica a los legos ante su falta de instrucción o ciencia, es así que el profesional con su desempeño, minimiza los peligros y riesgos que pudieran ocurrir por su actividad, disminuyendo cualquier responsabilidad que pudiera ocurrir en el desarrollo de su actividad.

Respecto a la actividad materialmente jurisdiccional ${ }^{7}$, es entendida como un trabajo con-

\footnotetext{
${ }^{5}$ BIBLIOTECA DEL IRC EN LA RED UNDERNET. Ética a Nicómaco-Aristóteles. Edición: Proyecto Espartaco Disponible en: http://www.uruguaypiensa.org.uy/imgnoticias/650.pdf. Acceso 20 enero 2016.

${ }^{6}$ ROLDÁN González J. Ética médica, Editorial Librería Parroquial de Clavería, México. 1990. Pág. 29

${ }^{7}$ La función materialmente jurisdiccional realizada por los órganos del poder judicial y órganos no jurisdiccionales consiste en la aplicación del derecho a los casos concretos que les son presentados en todo lo relacionado con la impartición de justicia, procedimiento y demás aspectos en protección de bien jurídico afectado; pero dicha función materialmente jurisdiccional entraña la posibilidad de causar un daño a los usuarios del sistema de impartición de justicia, por lo cual el error o negligencia ocasionada por esa actividad es atribuida al funcionario que materialmente resuelve sobre el problema planteado. MARROQUÍN Zaleta, Jaime Manuel. El error judicial inexcusable como causa
} 
junto con distribución de funciones, según el grado de cualificación. La distribución de funciones orgánicas en el organigrama judicial, contiene en la pluralidad de sus funciones, dificultades en conjunto, siendo esa globalidad la que incide en la función directiva del juez posicionándola además como riesgosa, que aun actuando como superior, no la ejecuta en realidad bajo la seguridad que exige su función, encaminando su posible actuación ilícita, directamente hacia su persona, sea por error y/o negligencia al impartir justicia.

La relación de causalidad entre un determinado comportamiento imprudente del funcionario judicial y el resultado dañoso producido, debiera ser atomizada orgánicamente, es decir, requiere de un pronunciamiento legal determinado por las competencias y responsabilidades que corresponde a cada uno de los participantes en la actividad judicial, al ser esta muy compleja y plural, estableciéndose la obligación jurídica del control de deberes como fuente de responsabilidad, ya que cada funcionalidad en conjunto puede incidir en el error y/o negligencia en la impartición de justicia.

De igual forma la institución orgánica de los tipos de irregularidades en la función jurisdiccional puede cumplir funciones de prevención general, haciendo efectivo los deberes de diligencia por parte no solo de los funcionarios, sino también de los auxiliares y técnicos en la impartición de justicia. El deber objetivo de cuidado $^{8}$, debe normativizarse en la producción de una lesión y peligro del bien jurídico comprometido y como también el comportamiento omisivo, consistente en la no realización de la acción tendiente a evitar el resultado dañoso, sino también la capacidad de acción en la evitación del resultado lesivo, cuando existiese la posibilidad real y material de evitar el resultado.

La complejidad que tiene el trabajo jurisdiccional en conjunto, obliga a la determinación de responsabilidades, tomando como punto de partida que cada uno es responsable de forma estrictamente personal ante el deber de cuidado; cuyo deber orgánicamente funcional individualizado tiene como punto original la confianza en el desempeño de las actividades asignadas, por ello cada uno de los participantes en el trabajo colegiado ha de tener la seguridad que los otros colman la garantía de cuidado encomendada en su función, caso contrario la funcionalidad se ve dañada por el quebrantamiento de un deber específico, afectándose de ese modo el resultado y el correcto

de responsabilidad administrativa. SCJN. México. 2001. nota 59. Pág. 15.

${ }^{8}$ TORIO López Ángel E1 deber objetivo de cuidado en los delitos culposos. 1974. Disponible en: https://dialnet.unirioja.es/descarga/articulo/2787923.pdf Acceso 20 Octubre 2016. 
desempeño en la impartición de justicia.

La conducta basada en la confianza de actuación sobre deberes de cuidado individualizado ante la distribución de una amplia gama de quehaceres jurisdiccionales, son conductas que unidas deben marchar coherentemente para lograr la encomienda conjunta; tal y como debería operar la funcionalidad de cualquier tribunal, por ello es sugerente y necesaria, tal y como hemos repetido, la determinación eficaz en el deber de protección que fije funcionalmente la distribución de las actividades irregulares con hipótesis claras para la adecuada imputación individualizada objetivamente en caso de requerirse en la ejecución de una actividad materialmente jurisdiccional.

De otra parte, la determinación de funciones, posibilita la atribución objetiva a los deberes de atención y cuidado de los órganos jurisdiccionales y sus funcionarios, crea mayor responsabilidad y legitima en su caso la sanción, por haber inobservado o incumplido el deber de no afectar terceros, en este caso en particular, los justiciables, de ahí que la responsabilidad sea atendida tomando la actuación del agente que directamente originó el daño no esperado por el gobernado; vinculo jurídico que se establece entre el débito y la responsabilidad, el deber de cumplir la prestación y la sujeción que se deriva del incumplimiento ${ }^{9}$ y conjuntamente la responsabilidad devenida, señala quien debe responder del cumplimento o incumplimiento de la obligación contraída ${ }^{10}$.

En la praxis jurídica, la incertidumbre que aparece en la normativa orgánica instruccional referente a la función jurisdiccional, entre los límites y las facultades inherentes a ella, ha dado como resultado que en ocasiones la atribución de hechos ilícitos cometidos en el ejercicio de las funciones, origine el encausamiento al operador judicial por algún tipo de responsabilidad, sea administrativa sancionadora o penal, bajo la sola premisa de la llamada responsabilidad o atribución objetiva, en el curso causal de los hechos, estableciéndose la sanción por la simple conducta de hacer, aún y cuando su función fuera concordante al contenido legal y al cumplimiento irrestricto de las garantías y principios que exigen la impartición de justicia.

Se ha divulgado que el error y/o negligencia materialmente jurisdiccional, puede ser declarado de "derecho" o de "hecho". En el primer caso, como acto que se ejecuta cuando el operador en la selección del derecho, equivoca, interpreta, o integra erróneamente los fundamentos norma-

\footnotetext{
${ }^{9}$ IGLESIAS, Juan. Derecho Romano. Historia e Instituciones. Editorial Ariel. S.A de C.V. Barcelona. 1987 Pág. 338-384

${ }^{10}$ TAMAYO y Salmorán, Rolando. Responsabilidad, Instituto de Investigaciones Jurídicas, Diccionario jurídico Mexicano. México. 2002, Pág. 3348-3350
} 
tivos, principios jurídicos, tratados internacionales y la jurisprudencia, que deban estimarse como correctamente aplicable; y de hecho al variar desatinadamente la acción, causa o prestación que se debate en el proceso, transformando la litis, o en cualquier supuesto resolviendo en contra de las constancias procesales; por lo cual como nexo de atribución y dependiendo de la lesión, será la sanción aplicable como falta administrativa excepto, en aquellos casos de posible conductas delictuosas, para lo que será menester, "una vez rebasado el estado del deber de cuidado, como criterio fundamentador de la imputación objetiva."11

En su generalidad el error y negligencia judicial, se ha considerado como la equivocación de un juez o magistrado cometida en el ejercicio del servicio público de administración de justicia, generadora de un daño ${ }^{12}$; o también como toda equivocación, inadvertencia, falta de atención o falsa apreciación de la realidad, derivado de un comportamiento intencional, imprudencial, o sin él; pudiéndose originar ese error judicial tanto en el funcionamiento normal o anormal de la administración de justicia ${ }^{13}$ y su expresión acontece cuando un órgano judicial superior, revoca la sentencia de otro inferior, motivo por el que implícitamente está declarando que la sentencia revocada es errónea en algún aspecto ${ }^{14}$.

Siendo el error o negligencia materialmente jurisdiccional resultado de la actividad irregular, que al producirse trae como consecuencia el daño en la esfera jurídica del gobernado, provocando lesión y afectación material al titular del "derecho sustantivo"15, como también, en la protección del derecho por la lesión y afectación material por la actuación del "derecho adjetivo", debe ser verificable por la actividad materialmente jurisdiccional, con elementos enunciativos y no limitativos.

En lo referente a la titularidad del derecho sustantivo; pudieran declararse como actividad irregular, algunas manifestaciones jurisprudenciales como son: fundar su actuar en un enunciado

\footnotetext{
${ }^{11}$ MUÑOZ Conde, Francisco y GARCÍA Aran, Mercedes. Derecho Penal, Parte General. Sexta edición. Editorial Tirant lo Blanch. Valencia. 1996 Pág. 258

${ }^{12}$ CIENFUEGOS Salgado, David. Responsabilidad estatal y error judicial en México. Lex. Difusión y Análisis. núm. 62. México, agosto de 2000. Pág. 19.

${ }^{13}$ RAZO García, Luis Alberto. El error judicial en materia penal. Concordancias, año 5, núm. 8, mayo-agosto de 2000. Pág. 209.

${ }^{14}$ HERNÁNDEZ Martín, Valeriano. El error judicial. Procedimiento para su declaración e indemnización”. Civitas. Madrid, 1994. Pág. 77.

${ }^{15} \mathrm{Al}$ respecto El artículo 107, fracción V, de la Ley de Amparo dispone que "Contra actos en juicio cuyos efectos sean de imposible reparación, entendiéndose por ellos los que afecten materialmente derechos sustantivos tutelados en la Constitución Política de los Estados Unidos Mexicanos y en los tratados internacionales de los que el Estado Mexicano sea parte; por lo cual "derechos sustantivos"no sólo deben entenderse los derechos humanos, sino también sus garantías previstas en el llamado parámetro de control de la regularidad constitucional.
} 
jurídico irreal, ya sea en su configuración hipotética, y/o alterando la gramática legislativa del mismo, y/o aplicándolo sin considerar su vigencia, y/o adecuándolo a hechos incompatibles, y/o interpretando la norma en sentido opuesto a su conocimiento o significado legal, a la que se arribó, conforme a la presunción de constitucionalidad otorgada.

Mientras que en lo pertinente a la titularidad del derecho adjetivo o instrumental, algunas irregularidades estarían relacionadas con omitir total o parcialmente el debido proceso, ya sea prescindiendo del llamamiento al justiciable para la defensa previa a la afectación o modificación jurídica que puede provocar el acto de autoridad, y/o considerar en su actuar la fijación errónea de los hechos relacionados con la acción ejercitada, y/o procediendo en contra de constancias procesales, y/o prescindiendo del material probatorio, tanto en su ofrecimiento, desahogo o valoración, y/o falta de pronunciamiento de resolución que dirima el debate jurídico y/o denegación prolongada de la justicia, y/o la inejecución de una sentencia como derecho declarado.

No se puede dejar de considerar que para la determinación de la existencia del error o negligencia, es necesario investigar si el pronunciamiento o acto de decisión fue emitido con mala fe, o si fueron suficientes los recursos jurídicos con los cuales se expresó el fallo, en todo caso, a las constancias del proceso y a las normas jurídicas aplicables, trátese como dice Marroquín de normas legislativas o de normas jurisprudenciales ${ }^{16}$. Además de que se tenga la posibilidad de ser corregido el error por algún medio de impugnación; ya que son supuestos de actuación materialmente jurisdiccionales que de no investigarse nos llevarían a estandarizar que existe error y negligencia en todas aquellas actuaciones o resoluciones de los juzgados o tribunales que han sido dejadas sin efecto.

Para poder establecer objetivamente el error y la negligencia judicial, tenemos que establecer y acreditar la culpa del infractor desde el derecho administrativo sancionador ${ }^{17}$, en la construcción de normas facultativas regladas, por ello es necesario abordar la conducta de los servidores públicos de la impartición de justicia como sujetos activos calificados, por la actividad que desempeñan, siendo calificados como sujetos activos culposos en el desempeño de su actividad irregular, por la inobservancia a su deber de cuidado tras la existencia de normas facultativas regladas.

Para que el desempeño de la actividad jurisdiccional, sea considerada irregular, supone

\footnotetext{
${ }^{16}$ MARROQUÍN, Ob., Cit. Pág. 8.

${ }^{17}$ URBANO Martínez, José Joaquín. La Legitimidad del Derecho Penal. Equilibrio entre fines, funciones y consecuencias. Universidad Externado de Colombia. Bogotá. Pág. 43.
} 
por tanto la infracción del deber de cuidado o como expresa Castellanos: “.. cuando se realiza la conducta sin encaminar la voluntad a la producción de un resultado típico, pero éste surge a pesar de ser previsible y evitable, por no ponerse en juego, por negligencia o por imprudencia, las cautelas o precauciones legalmente exigidas." 18

La necesidad de atribución sobre el error y la negligencia judicial, tiene su base en el desempeño de la impartición de justicia, cuyo nexo causal es ostensible, puesto que es materialmente jurisdiccional; actos que si bien pudieran hasta cierto punto ser legítimos por la función que dimana del encargo del poder del que emanan, también pueden ser irregulares en la administración de justicia, por la manifiesta lesión a la esfera jurídica de cualquier derecho del gobernado. Ello a la par evidencia un nexo de imputación por la actividad irregular que puede provocar daños y dicha atribución objetiva da nacimiento a la responsabilidad del funcionario judicial, ya que “.. cuando se causa un daño - dice Cienfuegos - nace una obligación respecto de su reparación, e incluso una sanción para el responsable."19

\section{Error y negligencia en la actividad de riesgo materialmente jurisdiccional}

Determinada el error y la negligencia en la actividad materialmente jurisdiccional, es oportuno reflexionar que estas instituciones gozan en su ejercicio de una la amplitud en su interpretación normativa, en la labor de la impartición de justicia, sin que pase desapercibido que cualquier actividad desarrollada por seres humanos, en ocasiones resulta ser equivocada, ya que el operador judicial está expuesto a muchos sucesos que pueden influir en su criterio, por lo cual, tanto la ley como la doctrina, han buscado establecer características de responsabilidad directa, con implicación en la realización de daño, por error, negligencia o dolo, dando pautas a hipótesis de actividad irregular de los órganos jurisdiccionales en el ejercicio de sus funciones.

Si bien la norma es el estatuto de los comportamientos funcionales reglados en la administración pública, la actividad materialmente jurisdiccional tiene en su quehacer el llamado riesgo permitido, del que se advierte el límite en su actuación sobre bienes ajenos, como pudieran ser aquellos pertenecientes a los justiciables, al respecto Herrera señaló que: "La existencia del riesgo permitido autoriza las actuaciones dentro de esa esfera de permisión, por lo que sin un resultado aparece dentro de ese cinturón permisivo, el resultado no podrá ser imputado bajo ninguna cir-

\footnotetext{
${ }^{18}$ CASTELLANOS Tena, Fernando. Lineamientos de Derecho Penal. Editorial Porrúa, México 1991. Pág. 246

${ }^{19}$ CIENFUEGOS, Ob. Cit. Págs. 12-13.
} 
cunstancia, lo contrario sería que el resultado ofreciera por haber excedido el límite de riesgo permitido." 20

El límite funcional del quehacer encomendado queda establecido en la norma, a través de la cual se describe la responsabilidad del funcionario, creando así el riesgo permitido en las hipótesis del deber de cuidado, cuestión que es social y utilitariamente aceptado; en la comprensión de que se puede imputar al sujeto la lesión que provoque, por desestabilizar el mismo con su comportamiento no permitido, o no adecuado.

Como antes se dijo, normativamente la actividad materialmente jurisdiccional en todo momento supone la capacidad profesional del funcionario antes de justipreciar los hechos puestos a su capacidad, por ello el riesgo de su quehacer es valorativo ex ante en la identificación del resultado, por lo que la atribución puede aclararse al emplear criterios normativos frente a las probidades tomadas en su comportamiento funcional adecuado o no.

La actividad materialmente jurisdiccional, es progresista y por necesidad establece actividades para vencer obstáculos o dificultades, con la finalidad de satisfacer necesidades y deseos de todos; y como muchas otras actividades, contribuye a superar dificultades que están relacionadas con ciertas circunstancias primordiales para vivir en sociedad, por lo que son permitidos, tolerados y adecuados.

El desarrollo de alguna actividad en cualquier ámbito, supone perfeccionamiento del área en progreso, ampliando la destreza, por lo cual el funcionamiento y el ejercicio normal se constituyen en la característica fundamental de la actividad proporcionada, otorgando seguridad o certeza; por ello una actividad de riesgo, es obrar suponiendo la proximidad de algún daño en su desarrollo, empero ello, si la sociedad lo ha permitido entonces la actividad se encuentra resguardada a través de la norma facultativa.

Bajo la desconfianza descansa la seguridad, por ello los riesgos inician donde acaba la confianza puesta en el riesgo permitido; la seguridad es asentada en la precaución donde se disminuye la amenaza al bien jurídicamente protegido, cualquiera que éste sea, ya que el peligro hacia su integridad existe. Las decisiones normativas y la fidelidad a esas hipótesis son protectoras específicamente hacia una conducta diligente, por ello la infidelidad normativa acarrea consecuencias al

\footnotetext{
${ }^{20}$ HERRERA Bazán Simón Pablo. Imputación Objetiva en el Juicio de Tipicidad. Primera edición. México. 2005. Págs. 288-289
} 
infractor; en ese sentido la disposición de incluir la precaución a las decisiones humanas trasforma progresivamente los peligros en riesgos.

Es evidente que al establecer la normativa adecuada a riesgos permitidos, íntimamente se establece la amenaza y provocación de un posible daño, con ello el peligro se ve contenido con las defensas adecuadas, evitando o disminuyendo la probabilidad de su causa, cuya delimitación normativa se adecua en el marco donde sea desarrollada la conducta.

El ser humano no asume riesgos de forma independiente, asume solo lo riesgos permitidos que le fueron dados a conocer por el Estado. La amenaza a bienes por lo tanto existe, porque la sociedad asume el riesgo como lícito, en consecuencia a cada riesgo permitido debe existir la precaución normativa para no desencadenar el peligro que provoque un daño y conjuntamente con el reconocimiento social, se registran las posibles consecuencias en la actividad, y por ello se asumen las responsabilidades que aunque no se persiguen son íntimas a ese riesgo jurídicamente tolerado.

Aceptar la actividad de riesgo positivamente permite adoptar medios de control como lo es la precaución para evitar daños, admitir que el Estado debe incluir en las salvaguardas de los gobernados los medios idóneos para garantizar la libertad de sus gobernados, es convalidar su función de protección, por lo cual no debe existir incertidumbre, en los mecanismos de defensa del ser humano.

La sociedad espera la existencia de un conjunto de valores, principios y fines, orientados a establecer las condiciones normativas necesarias e indispensables para la congruencia del desarrollo social armónico; propósitos que puede satisfacerse si los mandatarios del Estado y la ciudadanía cumplen con sus obligaciones, creyendo y respetando el orden jurídico; como derechos fundamentales, procurando con ello a la sociedad los elementos necesarios para acceder a la justicia.

Es primordial que el Estado y en particular las autoridades encargadas de la impartición de justicia, se sustenten en un marco jurídico que no se agote en la vigencia legal de las normas, sino que sea eficaz, claro, preciso, ágil, para que brinde certidumbre, igualdad, seguridad jurídica y legitimidad a sus actos; componentes que se tornan indispensables para la razón y funcionalidad de la sociedad, advirtiendo los comportamientos prohibidos e inhibiéndolos con sus respectivas sanciones, por ello debe ser versátil atendiendo las necesidades sociales, y su fuerza debe estar cubierta 
de una serie de garantías que la hagan privilegiada con normas eficaces en toda su funcionalidad.

La mencionada razón y funcionalidad, tiene como objeto que las necesidades sociales sean aceptadas en la convivencia socialmente aprobada, con ello se evitan determinados comportamientos sociales que se reputan indeseables, y que posteriormente se pueden traducir en conductas criminales, la confianza en la impartición de justicia debe ser confiable, garantizando su razón y validez, ante el orden jurídico y social, con ello se amplían válidamente las barreras de protección antes de la lesión a los bienes jurídicos protegidos.

Si bien la actividad materialmente jurisdiccional, en particular la impartición de justicia, en su función de interés público, por el logro del poder judicial ofrece el derecho cumpliendo la función de resolver conflictos entre los individuos y de proveer de ciertos medios para hacer posible la cooperación social; también lo es, que el desarrollo de la función del quehacer jurisdiccional debe ser preciso y valorado desde el punto de vista de la norma.

La determinación de la infracción del deber de cuidado en la impartición de justicia se debe analizar por la actividad que desarrolla el juez, ya no desde un mero proceso causal, sino desde la interpretación funcional en la protección de bienes jurídicos encomendados y que son valiosos para el justiciable; atendiendo a los limites valorativos de su función institucional la que es esperada por un comportamiento correcto vinculado a su obligación.

Solo infringe el deber de cuidado, aquella acción peligrosa que supera la medida normativamente permitida o adecuada socialmente, por tanto el riesgo permitido se fija de acuerdo a una medida objetiva y subjetivamente es calificada la persona que sea o no razonable y cuidadosa en la posición del autor en una situación concreta.

Determinar el nivel de riesgo permitido en la función jurisdiccional es ocurrir a conceptos normativos institucionales precisados como profesionista obligado y prudente. El riesgo permitido partiendo de la responsabilidad objetiva y basada en el riesgo asumido por el sujeto con su comportamiento, constituye el primer elemento de responsabilidad necesario para diferenciar la estructura normativa administrativa de la penal, toda vez que el riesgo permitido es relevante para la norma sancionadora, en función de su expectativa social.

No obstante la creación de un riesgo no permitido, un riesgo jurídicamente desaprobado o un riesgo típico, son elementos para la consumación de la conducta y ello obliga en la función del 
juzgador, a establecer normativamente la distinción entre el comportamiento lícito y el ilícito por el riesgo desaprobado o en su defecto el ilícito culposo o el ilícito doloso, como pauta idónea e instrumental apta para la protección a bienes jurídicos y como explicábamos para solventar los problemas de imputación con respecto al resultado del autor u otras y arbitrariedades en la imputación de una conducta indebida conforme a su ley orgánica.

Por ello el riesgo permitido desde la óptica orgánica en el ámbito de la impartición de justicia, debe gozar de reglamentos específicos sobre la conducta del funcionario judicial y sus agentes auxiliares en la protección de bienes jurídicos relacionados con el deber objetivo de cuidado; con ello se elimina el peligro contrario al fin de la norma; situación que hoy está ausente en muchos cuerpos legales. 